\title{
Validation of the Brief Questionnaire to Assess Habitual Beverage Intake (BEVQ-15) For Spanish Population
}

\author{
Karima Bouallalene-Jaramillo ${ }^{1 *}$, Alfonso Rodriguez -Baeza ${ }^{2}$ \\ ${ }^{1}$ Fisio7 Center, Spain \\ ${ }^{2}$ Morphological sciences department, UAB, Spain
}

Received: June 6, 2017; Accepted: June 16, 2017; Published:June 29, 2017

*Corresponding author: Karima Bouallalene-Jaramillo, Fisio7 Center, Sorolla 62, Sabadell, Barcelona, España. Tel: 679905592; E-mail: karimaboja@gmail.com

\begin{abstract}
Background and objective: Translate, cultural adaptation and validation of the questionnaire "Beverage Intake Questionnaire-15" (BEVQ-15) (validated in Virginia by Valisa E Hedrick) for use in the Spanish population. Design a tool that allows comparisons of changes in fluid intake.
\end{abstract}

Subjects and Methods: Translation and cultural adaptation was performed later recruit a sample of 512 people (average age of 48.25 years), which was presented two self-administrable questionnaires: the BEVQ-15 and food consumption. The latter used as Gold Standard.

Results: The reliability analysis showed good agreement between the first and second observation BEVQ-15 (IIC = 0'962), with Kappa range of 0'823 to 0'929 values.

Conclusion: The questionnaire translated and adapted version BEVQ-15 is a reliable, consistent and valid for assessing fluid intake in the Spanish population instrument.

Keywords: Validation; Fluid Intake

\section{Introduction}

Urinary incontinence is a health problem that is more frequent than is commonly thought, but often remains hidden; High prevalence are reported in different regions of the world $[1,2]$.

Urinary incontinence is more common in women. It is a problem, often ignored, that deteriorates the quality of life and has repercussions in the workplace. Urinary leakage is an important emotional and social burden for women and can also be a barrier to the development of physical activity and activity $[3,4]$.

Among the different risk factors that present the possibility of studying with urinary incontinence, we find that diet is also considered a risk factor, when we talk about the consumption of alcohol and coffee, where some studies find an association between coffee and urinary incontinence [5,6]. Women with high coffee consumption are associated with a greater predisposition regarding urinary incontinence, others more specific, commenting that there is a statistical association between coffee intakes in relation to the symptoms of urinary incontinence, except nocturnal, where caffeine is associated with urinary incontinence, but not stress and others not [7-13]. In terms of tea intake, it is associated with urinary incontinence, all of which depends on age [14]. Similarly, alcohol consumption, where the relationship has been found by some studies but not by others stating that alcohol consumption is associated with hyperactive detrusor, but not with stress urinary incontinence [10-12,15-19].

It has also been taken into account the intake of carbonated beverages, where a study finds relation [20]. Regarding fluid intake in relation to urinary incontinence, there is no relationship between them [21]. It has been specified that ingestion of fluid, 8 glasses per day, is not considered a risk factor for urinary incontinence [22].

Referring to diet, they report that fruit and bread consumption is associated with reduced risk of urinary incontinence. On the contrary, carbonized drinks increase the risk, whereas beer and coffee are not associated with incontinence [23].

Taking into account that the International Consultation on Incontinence (ICI) indicates that, in patients with urinary symptoms, the evaluation of the presence or absence of the symptom alone does not assess the impact of this problem on A more adequate way to assess symptoms and affect quality of life, is to collect the patient's opinion through the self-completion of robust evaluation questionnaires from the point of view of psychometric [24].

From this point of view, the Food Frequency Questionnaire is a tool within the nutritional assessment that allows measuring caloric consumption and the portion consumed according to the frequency of consumption of food groups in a person in days, weeks, months or years [25]. The tool describes what are the servings per week and per month and these are transformed to 
serving per day in such a way that the data is divided into 7 for portions per week and 30 for portions per month.

It consists of a closed list of foods on which the frequency of consumption of each of them is requested during a certain period. This questionnaire gives us global information on food intake over a broad period of time, the last 12 months, it is a questionnaire self-administered, which facilitates its viability to be used.

Although the information extracted is collected in a qualitative way, the incorporation of each food into the usual ration allows quantifying the consumption of food and nutrients.

The questionnaire of frequency of alimentary consumption, aims to determine the habitual frequency of intake of a food or group of foods during a period of time.

To obtain the validation that this work is used, they obtained a sample of 71 people between 13 and 65 years of age, recruited during a year. Standard Gold used the 24-hour reminder. Obtain good reproducibility with Spearman correlations between 0.49 and 0.75 for food and 0.44 and 0.78 for nutrients. So the correlations obtained with the highest value are reproducibility and good for validity. Therefore it is concluded that it is a valid instrument for the assessment of the usual intake of general food groups, energy and macronutrients, mainly vitamins. Being the questionnaire most used internationally.

On the other hand we find the questionnaire BEVQ-15 is the reduction of the BEVQ-19 questionnaire [26]. This initial questionnaire presents 19 items, which measures the frequency of consumption of beverages, as well as the amounts consumed, unlike other questionnaires where only the frequency of consumption is measured.

The BEVQ-19 questionnaire estimates daily average daily intake of water, beverages, as well as the consumption of kilocalories and grams consumed, through 19 categories of beverages, in addition to an open section for "other" unlisted beverages [27]. The beverage categories were initially established according to the energy and macronutrient content using food composition tables and the Nutrition Data System for Research software.

Respondents are asked to indicate "how often" and "how much" of a drink they consumed during the past month. The answers for the "how often" category range go from "never or less than once a week" to " 3 or more times a day". For the "how much" response, the range goes from less than one cup "to" two and a half cups. "

The initial step in the development of the BEVQ-19 (BEVQ15) was to first examine the cumulative frequencies to identify the beverage categories that contributed to $10 \%$ of the total energy of beverages and grams, or energy And grams, based on data from the BEVQ-19.

Population segments such as age, sex, race, BMI, education were evaluated to ensure that the categories of beverages consumed were not eliminated. They were evaluated individually to determine if the same beverage categories contributed $10 \%$ of the drink. The remaining drinks were then pooled to see if it was possible to combine elements into categories logically from the nutritional point of view and attest to the stability of the factorial structure.

For the validity of the reduced version of the BEVQ, a sample of 70 people who completed the BEVQ reduced self-administered questionnaire and three food intakes in 24 hours within the same week were followed up, with two working days and one Day of weekend The results were analyzed with Nutrition Software (Nutrition Data System for Research 2009 of the University of Minnesota). The validity was evaluated by the ingestion of the drinks (grams and kilocalories).

For this reason, this work performed the validation and cultural adaptation of BEVQ-15 as a tool for the assessment of fluid intake.

\section{Material and Methods}

To carry out this study, authorization has been requested for the use and validation of the BEVQ-15 questionnaire to the author of the questionnaire, Dr. Valisa Hecrick.

The original English version was translated by two bilingual people, with Spanish language of origin and graduates in English translation and interpretation (Aitor Sierra and Pedro Martínez). Both translations were discussed and agreed between the translators and the research team.

The conceptual equivalence, clarity and naturalness of each of the phrases as well as the response options were evaluated, applying the relevant modifications, such as the conversion of ounces to centiliters. Although it did not result in whole numbers, with the clarification of quantity in cups, there were no problems of compression.

Subsequently a meeting was held with health professionals and non-health professionals to know the opinion of the questionnaire.

The final version obtained has been retro-translated into English by two bilingual translators with English as their native language (Andrew Milton, sociologist and professor of English and Dominico Composto, with a degree in archeology and anthropology from Boston University)

\section{Subjects}

Recruitment was carried out by means of a sample of volunteers over 18 years of age stratified with proportionate. As exclusion criteria were considered those people who had difficulty understanding the text. The call was made in the media and in different institutions to which the researchers have access. A sample of 385 people, with a mean age of 48.25 years, was estimated from the calculation of the Spanish population over 18 years old $(37,230,407$ according to the 2016 census). For the analysis of the data a significance level of $\alpha=5 \%$, a power of $80 \%$, a minimum reliability of $\mathrm{p} 0=0.7$ and an approximate reliability of $\mathrm{p} 1=0.8$ were considered. With a loss estimate of $25 \%$, the final 
sample size was 512 subjects, taking into account possible losses, of which 181 were males and 331 females.

\section{Method}

Each participant was given an explanation of the purpose of the study as well as an informed consent document that they should accept.

The questionnaire consisted of a first section that included sociodemographic variables of the participants, and then the questions of the questionnaires selected for the study: the BEVQ15, which consisted of 15 questions, and the Frequency of dietary intake questionnaire, consisting of 45 questions. The latter used as Gold Standard in this study.

The two instruments allow the assessment of fluid intake, BEVQ-15 being more specific and the Frequency of dietary intake more comprehensive, since it incorporates a whole sequence of foods and only the last questions refer to fluid intake.

\section{Procedure for data collection}

In a first session, and having verified that the participants met the inclusion criteria and did not present exclusion criteria, the oral explanation of the study proceeded. With oral consent to participate in the study, the study documentation, as well as informed consent, was provided in paper format.

Once the consent was signed, participants were given the BEVQ-15 and Frequency of dietary intake questionnaires, as well as a sheet for the collection of sociodemographic variables.

At the end of the implementation of the questionnaires, the participants were placed within two weeks, since this period of time is considered sufficient to not respond by heart, while ensuring that there is no change in intake. After these two weeks, they were given the BEVQ-15 questionnaire again.

As a questionnaire complemented in a codified form, a code was used to identify the two documents, without knowing the source.

Once the entire sample was recruited, a first statistical analysis of the data was carried out, leading to the reliability and validity of the BEVQ-15 questionnaire, as well as the reproducibility and validity, being necessary for the use of the Standard Gold, Frequency of dietary intake

\section{Statistical analysis}

In order to evaluate the validity and reliability we calculated the internal consistency using the Cronbach coefficient, reliability Test-Retest, assessing intra-observer and inter-observer reliability, their concordance, using Kappa test, comparative methods, Using the Frequency of dietary intake as Standard Gold, and using the Interclass Correlation Coefficient (ICC) and the $95 \%$ confidence interval.

\section{Ethical Considerations}

dAt all times the Data Confidentiality Law (15/1999) was respected, the information obtained from the participants being anonymized.

The study project was approved by the Ethics and Animal and Human Experimentation Commission (CEEAH) of the Universitat Autònoma de Barcelona (procedure 2970 dated 08/05/2015, approved on 05/29/2015).

\section{Results}

The data were obtained from a sample of 512 people (181 males and 331 females), with the mean age being $48^{\prime} 25$ years, in men of 47'53 and in women of 48'60.The demographic variables used are, marital status, educational level and number of children, where we found a mean of 1.31 children. $1.8 \%$ married, $0.04 \%$ divorced, $0.31 \%$ unmarried and $0.04 \%$ widowed. With a level of studies $0.23 \%$ presents university studies, $0.310 \%$ average studies, $0.35 \%$ basic studies and 0.01 without studies.

\begin{tabular}{|c|c|c|c|}
\hline & Mean & Standard Deviation & $\begin{array}{c}\text { Confidence Interval } \\
\qquad 95 \%\end{array}$ \\
\hline BEVQ-15 (First. Grams/day) & $897^{\prime} 8627$ & $599 ’ 34426$ & [842'024-953'7007] \\
\hline BEVQ-15 (Second Grams/day) & $873^{\prime} 8980$ & $592 \prime 12946$ & [817’7729-930’0232] \\
\hline Frequency of dietary intake (Total. Grams/day) & $8002 ' 75593$ & $2607^{\prime} 99540$ & [7776'0985-8229'4201] \\
\hline \multirow[t]{2}{*}{$\begin{array}{l}\text { Frequency of dietary intake (Total liquid only. Grams/ } \\
\text { day) }\end{array}$} & $2778^{\prime} 6497$ & $1715^{\prime} 99281$ & [2629'5129-2927'7866] \\
\hline & $\alpha$ & ICC & IC $95 \%$ \\
\hline BEVQ-15 (First) - BEVQ-15 (Second) & $0 ’ 981$ & $0 ’ 962$ & [0’955-0’969] \\
\hline BEVQ-15 (First) - CFCA (Total) & $0^{\prime} 253$ & 0’147 & {$\left[0^{\prime} 052-0{ }^{\prime} 234\right]$} \\
\hline BEVQ-15 (Second) - CFCA (Total) & $0^{\prime} 254$ & 0’146 & [0’052-0’237] \\
\hline BEVQ-15 (First) - CFCA (Total only liquids) & $0 ’ 346$ & $0 ’ 209$ & {$\left[0{ }^{\prime} 118-0{ }^{\prime} 296\right]$} \\
\hline
\end{tabular}


Table 1 shows the descriptive results obtained. From these results it is noted that the first and second observations of the BEVQ-15 have a similar mean and standard deviation. Also, in both cases the confidence interval is narrow, indicating good precision in the estimation of the mean. In the case of the Frequency of dietary intake, differences in means are observed when calculating the total of the questionnaire, limiting the score to the assessments exclusively of liquids, presented in turn a confidence interval indicating good precision, as in the previous calculation.

The intra-observer reliability analysis is then performed, where the relation between the first and second observations of the BEVQ-15 questionnaire is calculated, as well as the total score of the Frequency of dietary intake questionnaire and the total score of the Frequency of dietary intake, only counting those referring to liquids.

Table 1 shows that the reliability between the first and second observations of the BEVQ-15 is very good (IIC = 0.962). The analysis performed to compare the total score of the Frequency of dietary intake and the only liquid score of that questionnaire, with the two observations of the BEVQ-15 show slight-regular reliability (IIC between 0'146 and 0'209).

The internal consistency between the first and second observations of the BEVQ-15, using the Crombach Alpha, is $\alpha=$ 0.981 , very close to 1 , indicating a very good reliability. In the case of the other comparatives, there are slight-regular values between the two observations of the BEVQ-15 regarding the total and only liquid scores of the Frequency of dietary intake. In the case of the two observations regarding the total score of liquids only gives us a higher value ( $\alpha=0.346$ and $\alpha=0.339$ ) than with the total score of the Frequency of dietary intake $(\alpha=0.254$ and $\alpha=0.253$ ).

When performing the concordance analysis, using the Kappa coefficient, between the first and second observations of the BEVQ-15, we obtain, observing each of the questions, presenting a total of 30 , values ranging from 0.823 being the lowest obtained And 0.929 the greater. All scores are close to 1, indicating a very good concordance, as shown in (Table 2).

\section{Discussion}

This study presents the validation to Spanish of the BEVQ-15 questionnaire, as a tool to assess fluid consumption. As Sabaté points out, there are different methods used for the evaluation of food consumption, the 24-hour Reminder being a useful tool for this purpose, the dietary journal allows to detail the quantities of food and beverages consumed [28-30]. The dietary history allows us to evaluate the average food and liquid intake as well as the frequency of consumption questionnaire, the latter being the most widely used, being validated in several languages such as Spanish , Chinese , Guam , for multiethnic populations , in Korean , Danish, Japanese, New Zealand, Brazil , Norway, Australia , among others [31,32,25,33-42].

In the review of the literature on specific tools that only assess fluid intake, we have verified that there are no questionnaires

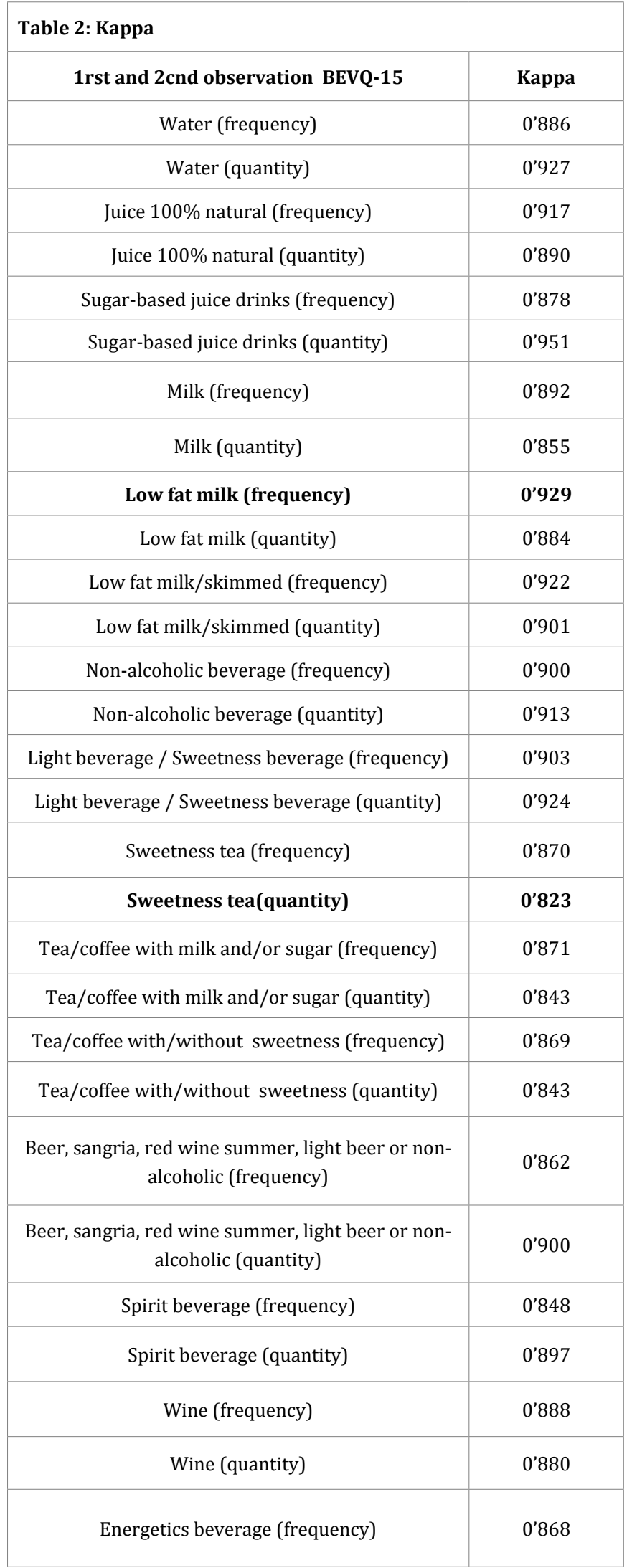


and / or self-reports for this purpose except BEVQ-19, created in 2012, and BEVQ- 15, which is an abbreviated version of the previous one, done in 2014 [27,26]. Nor have we found any publication that validates and adapts this questionnaire to other languages (since the questionnaire is in English and adapted to the American population)

In the study in Germany, they concluded that living donor nephrectomy appears to be a safe intervention in specialized centers where it entails a low morbidity for the donor. The overall major complications rate was $3.8 \%$ and minor complication rate was $21.9 \%$ [4]. Even in high risk donors, long term complications were not observed.

In our study, we compared the results obtained with the original version, finding that Cronbach's Alpha values are similar, with a range between 0'97-0'99 in the original version, compared to 0'981 in our study. This result allows us to consider a very good reliability [26].

When comparing methods with the Frequency of dietary intake, we observed a few light-regular values, all of which, when performing the analysis using only the questions that refer to fluid intake (discarding other foods), we obtain higher values ( $\alpha=$ 0.346 and $\alpha=0.339$ ). These values are still regular, which may be justified in the specificity of BEVQ-15 for fluid intake, compared to Frequency of dietary intake, which encompasses more items related to food intake.

To conclude the Kappa values, which indicate agreement, we can say that there is a very good, presented values from 0'823, this being the lowest, to 0'929 being the highest.

\section{Conclusions}

The study allows us to conclude that the Spanish version of the BEVQ-15 questionnaire that we have translated and adapted is a reliable, consistent and valid instrument for assessing fluid intake in the Spanish population.

\section{References}

1. Nihira MA, Henderson N. Epidemiology of urinary incontinence in women. Current Women's Health Reports. 2003;3(4):340-347.

2. Hunskaar S, Arnold E, Burgio K, Diokno A, Herzog A, Mallett V. Epidemiology and natural history of urinary incontinence. Int Urogynecol J.2000;11(5):301-319. doi:10.1007/s001920070021

3. Hunskaar S, Visnes A. The quality of life in women with urinary incontinence as measured by the sickness impact profile. J Am Geriatr Soc. 1991;39(4):378-382.

4. Crotty K, Bartram C, Pitkin J, Cairns M, Taylor P, Dorey G. Effect of Compartimental pelvic floor muscle contraction on urethrovesical structures using real time ultrasound - A Pilot study. Physiotherapy. 2007;(93):1-144.

5. Sherburn M, Guthrie JR, Dudley EC, O'Connell HE, Dennerstein L. Is incontinence associated with menopause? Obstet Gynecol. 2001;98(4):628-633.
6. Swanson JG, Kaczorowski J, Skelly J, Finkelstein M. Urinary incontinence: common problem among women over 45. Can Fam Physician. 2005;51:84-85.

7. Iosif CS, Békássy Z, Rydhström H. Prevalence of urinary incontinence in middle-aged women. Int J Gynaecol Obstet. 1988;26(2):255-259.

8. Foldspang A, Mommsen S, Lam GW, Elving L. Parity as a correlate of adult female urinary incontinence prevalence. J Epidemiol Community Health. 1992;46(6):595-600.

9. Brown JS, Seeley DG, Fong J, Black DM, Ensrud KE, Grady D. Urinary incontinence in older women: who is at risk? Study of Osteoporotic Fractures Research Group. Obstet Gynecol. 1996;87(5 Pt 1):715-721.

10. Bortolotti A, Bernardini B, Colli E, Di Benedetto P, Giocoli Nacci G, Landoni M. Prevalence and risk factors for urinary incontinence in Italy. Eur Urol. 2000;37(1):30-35.

11. Hannestad YS, Rortveit G, Sandvik H, Hunskaar S. A community-based epidemiological survey of female urinary incontinence: the Norwegian EPINCONT study. Epidemiology of Incontinence in the County of NordTrøndelag. J Clin Epidemiol. 2000;53(11):1150-1157.

12. Farquharson DI, Shingleton HM, Orr JW, Hatch KD, Hester S, Soong SJ. The short-term effect of radical hysterectomy on urethral and bladder function. British Journal Obstetrics and Gynaecology. 1987;94(4):351357.

13. Tähtinen RM, Auvinen A, Cartwright R, Johnson TM 2nd, Tammela TL, Tikkinen KA. Smoking and bladder symptoms in women. Obstet Gynecol. 2011;(3):643-648. doi: 10.1097/AOG.0b013e318227b7ac

14. Arya LA, Myers DL, Jackson ND. Dietary caffeine intake and the risk for detrusor instability: a case-control study. Obstet Gynecol. 2000;96(1):85-89.

15. Schmidbauer J, Temml C, Schatzl G, Haidinger G, Madersbacher S. Risk factors for urinary incontinence in both sexes. Analysis of a health screening project. Eur Urol. 2001;39(5):565-570.

16. Altman D, Ekström A, Forsgren C, Nordenstam J, Zetterström J Symptoms of anal and urinary incontinence following cesarean section or spontaneous vaginal delivery. Am J Obstet Gynecol. 2007;197(5):512.e1-7. doi: 10.1016/j.ajog.2007.03.083

17. Azuma R, Murakami K, Iwamoto M, Tanaka M, Saita N, Abe Y. Prevalence and risk factors of urinary incontinence and its influence on the quality of life of Japanese women. Nurs Health Sci. 2008;10(2):151-158. doi: 10.1111/j.1442-2018.2008.00390

18. Bhattacharya S, Mollison J, Pinion S, Parkin DE, Abramovich DR, Terry $\mathrm{P}$, et al. A comparison of bladder and ovarian function two years following hysterectomy or endometrial ablation. Br J Obstet Gynaecol. 1996;103(9):898-903.

19. Grady D, Brown JS, Vittinghoff E, Applegate W, Varner E, Snyder T. Postmenopausal hormones and incontinence: the Heart and Estrogen/ Progestin Replacement Study. Obstet Gynecol. 2001;97(1):116-120.

20. Steinauer JE, Waetjen LE, Vittinghoff E, Subak LL, Hulley SB, Grady D, 
et al. Postmenopausal hormone therapy: does it cause incontinence? Obstet Gynecol. 2005;106(5 Pt 1):940-945.

21. Ahmadi B, Alimohammadian M, Golestan B, Mahjubi B, Janani L, Mirzaei R. The hidden epidemic of urinary incontinence in women: a population-based study with emphasis on preventive strategies. Int Urogynecol J. 2010;21(4):453-459. doi: 10.1007/s00192-009-1031-6

22. Teleman PM, Lidfeldt J, Nerbrand C, Samsioe G, Mattiasson A; WHILA study group. Overactive bladder: prevalence, risk factors and relation to stress incontinence in middle-aged women. BJOG. 2004 Jun;111(6):600-4. doi: 10.1111/j.1471-0528.2004.00137

23. Amaro JL, Macharelli CA, Yamamoto H, Kawano PR, Padovani $\mathrm{CV}$, Agostinho AD.Prevalence and risk factors for urinary and fecal incontinence in Brazilian women. International Brazilian Journal of Urology. 2009;35(5):592-597. doi: 10.1590/S167755382009000500011

24.Penson D, Litwin M. Calidad de vida relacionada con la salud en pacientes con cánceres urológicos. AUA. Actualización en Urología. Edición Española. 1998;1:29-34.

25. Rodríguez T, Ferández J, Cucó G, Biarnés E, Arija V. Validación de un cuestionario de frecuencia de consumo alimentario corto: reproducibilidad y validez. Nutr Hosp. 2008;23(3):242-252.

26. Hedrick VE, Savla J, Comber DL, Flack KD, Estabrooks PA, Nsiah-Kumi PA, et al. Development of a brief questionnaire to assess habitual beverage intake (BEVQ-15): sugar-sweetened beverages and total beverage energy intake. J Acad Nutr Diet. 2012;112(6):840-849. doi: 10.1016/j.jand.2012.01.023

27. Hedrick VE, Comber DL, Estabrooks PA, Savla J, Davy BM. The beverage intake questionnaire: determining initial validity and reliability. J Am Diet Assoc. 2010;110(8):1227-1232. doi: 10.1016/j.jada.2010.05.005

28. Sabaté J. Estimación de la ingesta dietética: métodos y desafíos. Med Clin (Barc). 1993;100(15):591-596.

29. Calkins BM, Whittaker DJ, Nair PP, Rider AA, Turjman N. Diet, nutrition intake, and metabolism in populations at high and low risk for colon cancer. Nutrient intake. Am J Clin Nutr. 1984;40(4 Suppl):896-905.

30. Mertz W, Kelsay JL. Rationale and design of the Beltsville one-year dietary intake study. Am J Clin Nutr. 1984;40(6 Suppl):1323-1326.

31. van Staveren WA, de Boer J0, Burema J. Validity and reproducibility of a dietary history method estimating the usual food intake during one month. Am J Clin Nutr. 1985;42(3):554-559.

32. Willett WC, Sampson L, Stampfer MJ, Rosner B, Bain C, Witschi J, et al. Reproducibility and validity of a semiquantitative food frequency questionnaire. Am J Epidemiol. 1985;122(1):51-65.
33. Zhang H, Qiu X, Zhong C, Zhang K, Xiao M, Yi N, et al. Reproducibility and relative validity of a semi-quantitative food frequency questionnaire for Chinese pregnant women. Nutr J. 2015;14:56. doi: 10.1186/ s12937-015-0044

34. Leon Guerrero RT, Chong M, Novotny R, Wilkens LR, Badowski G, Blas-Laguana $\mathrm{M}$, et al. Relative validity and reliability of a quantitative food frequency questionnaire for adults in Guam. Food Nutr Res. 2015;59:26276. doi: 10.3402/fnr.v59.26276

35. Ollberding NJ, Gilsanz V, Lappe JM, Oberfield SE, Shepherd JA. Reproducibility and intermethod reliability of a calcium food frequency questionnaire for use in Hispanic, non-Hispanic Black, and non-Hispanic White youth. J Acad Nutr Diet. 2015;115(4):519-527. doi: 10.1016/j.jand.2014.12.016

36. Joh HK, Oh SW, Lee E. Reproducibility and validity of semi-quantitative food frequency questionnaire measuring dietary trans-fatty acids intake among Korean adults. Nutr Res Pract. 2015;9(1):99-105. doi: 10.4162/nrp.2015.9.1.99

37. Vuholm S, Lorenzen JK, Kristensen M. Relative validity and reproducibility of a food frequency questionnaire to assess dietary fiber intake in Danish adults. Food Nutr Res. 2014;58:24723. doi: 10.3402/fnr.v58.24723

38. Maruyama K, Kokubo Y, Yamanaka T, Watanabe M, Iso H, Okamura T, et al. The reasonable reliability of a self-administered food frequency questionnaire for an urban, Japanese, middle-aged population: the Suita study. Nutr Res. 2015;35(1):14-22. doi: 10.1016/j. nutres.2014.10.012

39. Mills VC, Skidmore PM, Watson EO, Taylor RW, Fleming EA, et al. Relative validity and reproducibility of a food frequency questionnaire for identifying the dietary patterns of toddlers in New Zealand. J Acad Nutr Diet. 2015;115(4):551-8. doi: 10.1016/j.jand.2014.09.016

40. Selem SS, Carvalho AM, Verly-Junior E, Carlos JV, Teixeira JA, Marchioni DM, et al. Validity and reproducibility of a food frequency questionnaire for adults of São Paulo, Brazil. Rev Bras Epidemiol. 2014;17(4):852859.

41. Overby NC, Johannesen E, Jensen G, Skjaevesland AK, Haugen M. Test-retest reliability and validity of a web-based food-frequency questionnaire for adolescents aged 13-14 to be used in the Norwegian Mother and Child Cohort Study (MoBa). Food Nutr Res. 2014;17:58. doi: $10.3402 /$ fnr.v58.23956

42. Somerset S, Papier K. A food frequency questionnaire validated for estimating dietary flavonoid intake in an Australian population. Nutr Cancer. 2014;66(7):1200-1210. doi: 10.1080/01635581.2014.951728 